\title{
Subclinical Hypothyroidism Is an Independent Risk Factor for Atherosclerosis and Myocardial Infarction in Elderly Women: The Rotterdam Study
}

\author{
A. Elisabeth Hak, MD, MSc; Huibert A.P. Pols, MD, PhD; Theo J. Visser, MD, PhD; \\ Hemmo A. Drexhage, MD, PhD; Albert Hofman, MD, PhD; and Jacqueline C.M. Witteman, PhD
}

Background: Overt hypothyroidism has been found to be associated with cardiovascular disease. Whether subclinical hypothyroidism and thyroid autoimmunity are also risk factors for cardiovascular disease is controversial.

Objective: To investigate whether subclinical hypothyroidism and thyroid autoimmunity are associated with aortic atherosclerosis and myocardial infarction in postmenopausal women.

Design: Population-based cross-sectional study.

Setting: A district of Rotterdam, the Netherlands.

Participants: Random sample of 1149 women (mean age $\pm S D, 69.0 \pm 7.5$ years) participating in the Rotterdam Study.

Measurements: Data on thyroid status, aortic atherosclerosis, and history of myocardial infarction were obtained at baseline. Subclinical hypothyroidism was defined as an elevated thyroid-stimulating hormone level $(>4.0$ $\mathrm{mU} / \mathrm{L}$ ) and a normal serum free thyroxine level (11 to 25 $\mathrm{pmol} / \mathrm{L}$ [0.9 to $1.9 \mathrm{ng} / \mathrm{dL}]$ ). In tests for antibodies to thyroid peroxidase, a serum level greater than $10 \mathrm{IU} / \mathrm{mL}$ was considered a positive result.

Results: Subclinical hypothyroidism was present in $10.8 \%$ of participants and was associated with a greater age-adjusted prevalence of aortic atherosclerosis (odds ratio, 1.7 [95\% Cl, 1.1 to 2.6$]$ ) and myocardial infarction (odds ratio, 2.3 [Cl, 1.3 to 4.0]). Additional adjustment for body mass index, total and high-density lipoprotein cholesterol level, blood pressure, and smoking status, as well as exclusion of women who took $\beta$-blockers, did not affect these estimates. Associations were slightly stronger in women who had subclinical hypothyroidism and antibodies to thyroid peroxidase (odds ratio for aortic atherosclerosis, $1.9[\mathrm{Cl}, 1.1$ to 3.6$]$; odds ratio for myocardial infarction, $3.1[\mathrm{Cl}, 1.5$ to 6.3$])$. No association was found between thyroid autoimmunity itself and cardiovascular disease. The population attributable risk percentage for subclinical hypothyroidism associated with myocardial infarction was within the range of that for known major risk factors for cardiovascular disease.

Conclusion: Subclinical hypothyroidism is a strong indicator of risk for atherosclerosis and myocardial infarction in elderly women.

Ann Intern Med. 2000;132:270-278.

For author affiliations, current addresses, and contributions, see end of text.
$\mathrm{O}$ vert hypothyroidism, with its accompanying hypercholesterolemia and hypertension, has been found to be associated with cardiovascular disease (1-3). Subclinical hypothyroidism, defined as an asymptomatic state characterized by normal serum concentrations of free thyroxine and elevated serum concentrations of thyroid-stimulating hormone (TSH) (4), is highly prevalent in elderly women $(5,6)$. Whether subclinical hypothyroidism is related to risk for cardiovascular disease is controversial. Case-control and cross-sectional studies on the association between subclinical hypothyroidism and cardiovascular disease have been done (7-11). Results from these studies are not consistent, but many of the studies were small. The same controversy surrounds thyroid autoimmunity. In the late 1960 s and early 1970s, autopsy studies $(12,13)$ and studies in hospital inpatients $(12,14)$ suggested that asymptomatic autoimmune thyroiditis was an important risk factor for coronary heart disease. These findings, however, were not confirmed by other studies $(7,8,11,15)$.

In our population-based study, we examined whether subclinical hypothyroidism and thyroid autoimmunity are associated with aortic atherosclerosis and myocardial infarction in elderly women. We conducted our study in a random sample of 1149 postmenopausal women who were participating in the Rotterdam Study.

\section{Methods}

\section{The Rotterdam Study}

The Rotterdam Study is a population-based cohort study designed to assess the occurrence and clarify the determinants of chronic diseases in an aging population (16). The cohort includes 3105 men and 4878 women at least 55 years of age (78\% of the eligible population) living in a defined district in Rotterdam, the Netherlands. Baseline data were collected from August 1990 to July 1993. During a home interview, a trained research assistant gathered information on current and past health, medication, lifestyle, and risk factors for chronic diseases. Participants were subsequently invited to visit a research center for clinical examination. The study 
was approved by the medical ethics committee of Erasmus University Medical School, Rotterdam, the Netherlands.

\section{Clinical Examination and Laboratory Methods}

Height and weight were measured while each participant was wearing indoor clothing without shoes. Body mass index was computed as weight divided by height squared. A trained research assistant measured sitting systolic and diastolic blood pressure with a random-zero sphygmomanometer after 5 minutes of rest, and a standard 12-lead electrocardiogram was obtained (ACTA electrocardiogram recorder, Esoate, Florence, Italy).

Venipuncture was performed, and nonfasting serum samples were collected. The samples were immediately put on ice and were processed within 30 minutes, after which they were kept frozen at $-20^{\circ} \mathrm{C}$. We used an automated enzymatic procedure to determine serum total cholesterol level (17). High-density lipoprotein (HDL) cholesterol levels were measured in a similar manner after precipitation of the non-HDL cholesterol fraction. Total protein level was measured by using the biuret method, albumin level was measured by using the bromocresolgreen method, and creatinine concentration was measured by using an enzymatic colorimetric method. (All products were manufactured by Boehringer Mannheim, Mannheim, Germany, currently Roche Diagnostics, Basel, Switzerland.) We assayed levels of TSH by using TSH Lumitest (Henning, Berlin, Germany, currently Brahms, Berlin, Germany) (18). When TSH concentrations were abnormal $(>4.0 \mathrm{mU} / \mathrm{L}$ or $<0.4 \mathrm{mU} / \mathrm{L})$, serum free thyroxine levels were measured with an in vitro immunodiagnostic reagent (Ortho-Clinical Diagnostics, Amersham, England, United Kingdom); values between 11 and $25 \mathrm{pmol} / \mathrm{L}(0.9$ and $1.9 \mathrm{ng} / \mathrm{dL})$ were considered normal. Serum antibodies to thyroid peroxidase were assessed by using enzyme-linked immunosorbent assay (Milenia, DPC, Los Angeles, California); test results were considered positive if levels were greater than $10 \mathrm{IU} / \mathrm{mL}$.

\section{Thyroid Definitions}

Subclinical hypothyroidism was defined as a TSH level greater than $4.0 \mathrm{mU} / \mathrm{L}$ in the presence of a normal free thyroxine level ( 11 to $25 \mathrm{pmol} / \mathrm{L}$ [ 0.9 to $1.9 \mathrm{ng} / \mathrm{dL}])$. Clinical hypothyroidism was defined as a TSH level greater than $4.0 \mathrm{mU} / \mathrm{L}$ and a decreased free thyroxine level ( $<11 \mathrm{pmol} / \mathrm{L}[<0.9 \mathrm{ng} / \mathrm{dL}])$ (4). Euthyroidism was defined as a normal TSH level (0.4 to $4.0 \mathrm{mU} / \mathrm{L})$.

\section{Aortic Atherosclerosis}

Aortic atherosclerosis was assessed on a lateral radiographic film of the lumbar spine, which was obtained from a fixed distance while the participants were seated. A researcher who was unaware of the participants' thyroid status diagnosed atherosclerosis off-line by detecting calcified deposits in the abdominal aorta, as described elsewhere $(19,20)$. Calcification was considered present when linear densities were found in an area parallel and anterior to the lumbar spine (L1 to L4). We classified aortic atherosclerosis as mild, moderate, or severe, according to the length of the involved area $(\leq 1 \mathrm{~cm}, 2$ to 5 $\mathrm{cm}$, and $>5 \mathrm{~cm}$, respectively). Because of a relatively small number of participants in the categories of aortic atherosclerosis, we combined severity grades into two categories- "present" or "absent"for analysis.

The validity of radiographic assessment of aortic atherosclerosis has been studied by comparing results of this method with data obtained at autopsy. Radiographic assessment was shown to be highly specific, and in most cases visible calcification represented advanced intima atherosclerosis (21). A comparison study involving computed tomography was performed at our department. In 56 unselected elderly persons, aortic calcifications were independently assessed by radiography and computed tomography. Calcifications were detected on abdominal radiography in 32 persons. In all but 1 person, these calcifications were shown to be located in the aorta on the corresponding computed tomography images (20).

Aortic calcification is known to be associated with risk factors for cardiovascular disease $(19,20)$ and with atherosclerosis at other sites (22) and predicts cardiovascular morbidity and mortality (23, $24)$. When aortic calcification (as detected by radiography) was compared with coronary artery calcium (as detected by electron-beam computed tomography) in 457 participants in the Rotterdam Study, aortic calcification was present in $3.9 \%$ of participants in the lowest tertile of coronary artery calcium, in $13.7 \%$ of those in the middle tertile of coronary artery calcium, and in $31.5 \%$ of those in the highest tertile of coronary artery calcium $(P<0.001$ for trend, adjusted for age and sex $)$. These results indicate that aortic calcification is strongly related to coronary calcification.

\section{Myocardial Infarction at Baseline}

The presence of myocardial infarction was assessed by self-report and by analysis of the standard 12-lead electrocardiograms, which were stored digitally and were analyzed by using the Modular Electrocardiogram Analysis System (MEANS) (25, 26). For participants who reported myocardial infarction but had no electrocardiographic evidence of it, we collected additional information from their general practitioners or cardiologists. Myocardial infarction 


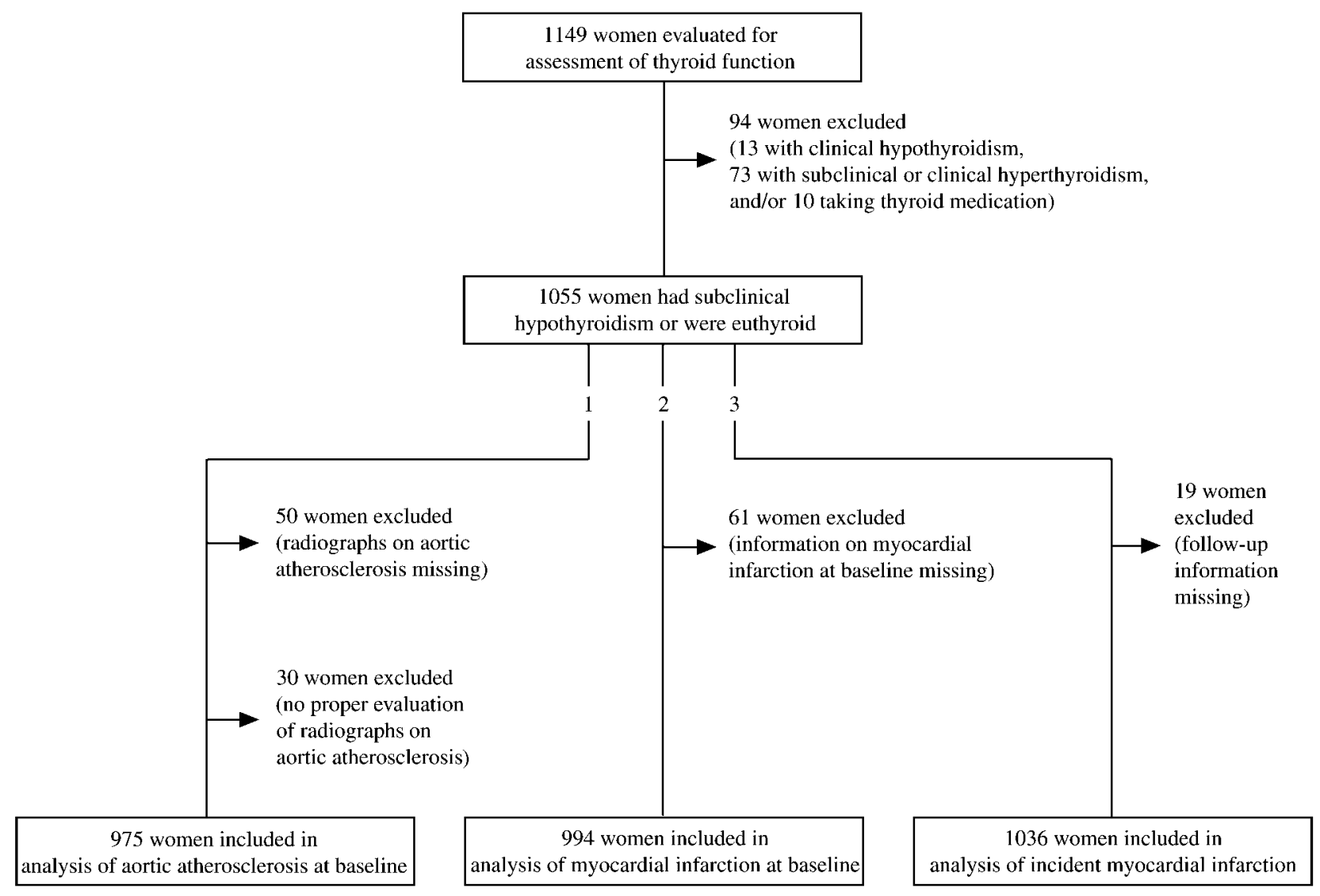

Figure. Selection of sample for analysis. 1 = selection of women for analysis of aortic atherosclerosis at baseline; 2 = selection of women for analysis of history of myocardial infarction at baseline; 3 = selection of women for analysis of incident myocardial infarction.

was confirmed if the information in the medical records met standard diagnostic criteria. An experienced cardiologist reviewed the electrocardiograms of participants who had not reported myocardial infarction but had electrocardiographic evidence of it. In these participants, absence of symptoms was confirmed by medical records review. When the cardiologist confirmed myocardial infarction (silent myocardial infarction), it was considered present. We combined both types of myocardial infarction into one variable for analysis. No information on the thyroid status of participants was available at assessment for myocardial infarction.

\section{Follow-up Procedures}

We collected data on incident myocardial infarction from baseline (1990 to 1993) until 1 April 1996. Fatal and nonfatal events were reported by general practitioners in the research area (in which $85 \%$ of the study cohort resides) who cooperate with the Rotterdam Study and provide information through a computerized system. Research physicians verified all information by checking participants' medical records at the general practitioners' offices. In addition, we obtained letters from medical specialists and discharge reports for hospitalized patients. Two research physicians coded events independently according to the International Classification of Diseases, 10th Revision (27). If the two physicians disagreed, they reached consensus in a separate session. Subsequently, a medical expert in the field reviewed all events coded by the research physicians and verified that all coding rules had been applied correctly. When discrepancies were found between the coding of the medical expert and that of the research physicians, the expert's judgment was considered final. Myocardial infarction was defined as a nonfatal or fatal myocardial infarction (ICD-10 codes I21-I23). When we compared our results with data registered by the nationwide morbidity registry of hospitals, we found that $98 \%$ of all incident myocardial infarctions that occurred in Rotterdam Study participants before 1 April 1996 had been detected by our follow-up data collection system.

\section{Selection of the Sample for Analysis}

The selection of the sample for analysis is shown in the Figure. We determined thyroid status in a random sample of 1149 women after excluding those who took amiodarone, which may nonsystematically alter TSH levels (28). To obtain a reference category that included only euthyroid women (those 


\begin{tabular}{|c|c|c|}
\hline Variable & $\begin{array}{l}\text { Euthyroid Women } \\
\qquad(n=931)^{*}\end{array}$ & $\begin{array}{l}\text { Women with Subclinical Hypothyroidism } \\
\qquad(n=124) \dagger\end{array}$ \\
\hline Mean age $\pm S D, y$ & $68.9 \pm 7.4$ & $69.0 \pm 7.9$ \\
\hline Mean body mass index $\pm \mathrm{SD}, \mathrm{kg} / \mathrm{m}^{2}$ & $26.7 \pm 4.1$ & $27.1 \pm 3.8$ \\
\hline Mean systolic blood pressure $\pm \mathrm{SD}, \mathrm{mm} \mathrm{Hg}$ & $138 \pm 21$ & $137 \pm 22$ \\
\hline Mean diastolic blood pressure $\pm \mathrm{SD}, \mathrm{mm} \mathrm{Hg}$ & $73 \pm 11$ & $73 \pm 11$ \\
\hline Mean total cholesterol level \pm SD, $\mathrm{mmol} / \mathrm{L}(\mathrm{mg} / \mathrm{dL})$ & $7.0 \pm 1.2(271 \pm 46)$ & $6.7 \pm 1.0(259 \pm 39) \neq$ \\
\hline Mean high-density lipoprotein cholesterol level \pm SD, $\mathrm{mmol} / \mathrm{L}(\mathrm{mg} / \mathrm{dL})$ & $1.5 \pm 0.4(58 \pm 15)$ & $1.4 \pm 0.4(54 \pm 15) \S$ \\
\hline Mean total protein level $\pm S D, g / L$ & $71.0 \pm 4.9$ & $71.7 \pm 4.7$ \\
\hline Mean albumin level $\pm S D, g / L$ & $42.7 \pm 2.4$ & $43.0 \pm 2.5$ \\
\hline Mean creatinine concentration $\pm \mathrm{SD}, \mu \mathrm{mol} / \mathrm{L}(\mathrm{mg} / \mathrm{dL})$ & $77.6 \pm 13.9(0.9 \pm 0.2)$ & $77.4 \pm 14.7(0.9 \pm 0.2)$ \\
\hline \multicolumn{3}{|l|}{ Smoking status, \% $(n)$} \\
\hline Never & $50(466)$ & $51(63)$ \\
\hline Past & $29(272)$ & 30 (37) \\
\hline Current & 19 (176) & $19(23)$ \\
\hline
\end{tabular}

whose TSH levels were within the normal range), we excluded women with clinical hypothyroidism $(n=13)$; those with a decreased TSH level $(<0.4 \mathrm{~m}$ $\mathrm{U} / \mathrm{L}$ ), which indicated clinical hyperthyroidism (free thyroxine level $>25 \mathrm{pmol} / \mathrm{L}[>1.9 \mathrm{ng} / \mathrm{dL}])$ or subclinical hyperthyroidism (free thyroxine level, 11 to $25 \mathrm{pmol} / \mathrm{L}$ [0.9 to $1.9 \mathrm{ng} / \mathrm{dL}])(n=73)$; and/or those taking thyroid medication (L-thyroxine or thyrostatic medication [propylthiouracil, carbimazole, or thiamazole] $)(n=10)$.

Of the 1055 women remaining, we excluded those for whom data were missing $(n=50)$ or improper $(n=30)$; therefore, 975 were included in our analysis of aortic atherosclerosis (Figure, selection 1). Data on myocardial infarction at baseline were available for 994 women (Figure, selection 2). At the time of analysis, 19 women had not been completely followed because of linking problems between their general practitioners' medical records and our computerized registration system. Therefore, until 1 April 1996, completed follow-up for analysis of incident myocardial infarction was available for 1036 women, covering an average period $( \pm \mathrm{SD})$ of $4.6 \pm 0.7$ years (Figure, selection 3$)$.

\section{Statistical Analysis}

We used linear regression analysis to compare the age-adjusted continuous baseline characteristics of euthyroid women and women with subclinical hypothyroidism. The chi-square test was used to compare proportions of women who smoked in both groups and to compare proportions of women who had subclinical hypothyroidism and antibodies to thyroid peroxidase according to vascular disease status.

Multivariate logistic regression analysis was used to evaluate the association of aortic atherosclerosis and myocardial infarction as assessed at baseline (history of myocardial infarction) with subclinical hypothyroidism. For women with subclinical hypo- thyroidism, we computed the risk for incident myocardial infarction (both fatal and nonfatal) during follow-up by using Cox proportional hazards regression analysis. In this analysis, we excluded women with a history of myocardial infarction $(n=79)$. We adjusted all analyses for age by entering age as a continuous variable in the regression model; we subsequently adjusted analyses for body mass index, cholesterol and HDL cholesterol level, systolic and diastolic blood pressure, and smoking status (never, past, or current). To ensure that comparisons between models were valid, the age-adjusted models included the number of participants for whom information was available on all of the covariates for which the multivariate model was adjusted.

We performed additional analyses after excluding women who took $\beta$-blockers (alprenolol, oxprenolol, pindolol, propranolol, timolol, and sotalol) $(n=37)$ because these drugs may influence TSH levels (29). In addition, we used logistic regression analysis to compare the associations of aortic atherosclerosis and history of myocardial infarction with subclinical hypothyroidism in women who had subclinical hypothyroidism and antibodies to thyroid peroxidase relative to those in euthyroid women who did not have antibodies to thyroid peroxidase. We also used logistic regression analysis to compare the frequency of aortic atherosclerosis and history of myocardial infarction in women with antibodies to thyroid peroxidase and women without antibodies to thyroid peroxidase, independent of thyroid status.

The attributable risk percentage, or etiologic fraction, and the population attributable risk percentage for subclinical hypothyroidism associated with incident myocardial infarction were calculated (30). For purposes of comparison, we calculated the attributable risk percentage and the population attributable risk percentage for the four major, classic risk factors for cardiovascular disease-hypercholes- 
terolemia (total cholesterol level $\geq 8.0 \mathrm{mmol} / \mathrm{L}$ [ $\geq 309 \mathrm{mg} / \mathrm{dL}]$ ), hypertension (systolic blood pressure $\geq 160 \mathrm{~mm} \mathrm{Hg}$ and/or diastolic blood pressure $\geq 95 \mathrm{~mm} \mathrm{Hg}$, and/or antihypertensive medication use), smoking status (current and past compared with never), and diabetes mellitus (use of antidiabetic medication or a random postload glucose level $>11.1 \mathrm{mmol} / \mathrm{L}[200 \mathrm{mg} / \mathrm{dL}]$ ) —associated with incident myocardial infarction in all female participants of the Rotterdam Study $(n=4878)$.

All measures of association are presented with 95\% CIs. A $P$ value less than 0.05 was considered statistically significant. We used SPSS 8.0 for Windows (SPSS, Inc., Chicago, Illinois) for all analyses.

\section{Results}

Before exclusion of clinically hypothyroid women, women with a decreased TSH level, and women using thyroid medication, the prevalence of subclinical hypothyroidism in the study sample was $10.8 \%$. The baseline characteristics of the study sample are shown in Table 1. Women with subclinical hypothyroidism did not differ from euthyroid women with regard to age, body mass index, blood pressure, total protein level, albumin level, creatinine concentration, or smoking status but had significantly lower levels of total cholesterol and borderline significantly lower levels of HDL cholesterol in age-adjusted comparisons.

Table 2 shows the characteristics of participants according to vascular disease status. Fifty-three percent of participants $(n=560)$ had aortic atherosclerosis at baseline, and $7.5 \%(n=79)$ had a history of myocardial infarction. Subclinical hypothyroidism was present in $11.8 \%$ of women in our sample for analysis. Women who had aortic atherosclerosis and a history of myocardial infarction had a higher prevalence of subclinical hypothyroidism and subclinical hypothyroidism accompanied by antibodies to thyroid peroxidase than those who did not have these diseases. The prevalence of thyroid autoimmunity independent of thyroid status itself did not differ significantly among the specific subgroups. Among women with subclinical hypothyroidism, concentrations of TSH were higher in those with antibodies to thyroid peroxidase than in those without such antibodies (age-adjusted geometric means, 6.6 $\mathrm{mU} / \mathrm{L}$ [CI, 6.1 to $7.1 \mathrm{mU} / \mathrm{L}]$ and $5.4 \mathrm{mU} / \mathrm{L}$ [CI, 5.0 to $5.8 \mathrm{mU} / \mathrm{L}]$, respectively; $P=0.001)$. Independent of thyroid status, TSH levels were also higher in women who had antibodies to thyroid peroxidase than in those who did not (geometric means, 2.4 $\mathrm{mU} / \mathrm{L}$ [CI, 2.2 to $2.6 \mathrm{mU} / \mathrm{L}]$ and $1.6 \mathrm{mU} / \mathrm{L}$ [CI, 1.5 to $1.7 \mathrm{mU} / \mathrm{L}]$, respectively; $P<0.001$ ).

Subclinical hypothyroidism was associated with a greater prevalence of aortic atherosclerosis. The odds ratio for aortic atherosclerosis (1.7 [CI, 1.1 to 2.6]) was increased in women with subclinical hypothyroidism (Table 3). Women with subclinical hypothyroidism also had a greater prevalence of myocardial infarction than euthyroid women (odds ratio, 2.3 [CI, 1.3 to 4.0]) (Table 3). Additional adjustment for body mass index, total cholesterol and HDL cholesterol levels, systolic and diastolic blood pressure, and smoking status did not affect these associations, nor did exclusion of participants who used $\beta$-blockers (data not shown). During an average follow-up of 4.6 years, 16 women had a first incident myocardial infarction. When we used a Cox proportional hazards regression analysis in women with subclinical hypothyroidism, a statistically nonsignificant adjusted relative risk of 2.5 (CI, 0.7 to 9.1) was observed for myocardial infarction.

Women with subclinical hypothyroidism and antibodies to thyroid peroxidase had a greater prevalence of aortic atherosclerosis than euthyroid women without antibodies to thyroid peroxidase (odds ratio, 1.9 [CI, 1.1 to 3.6]) (Table 3). The presence of antibodies to thyroid peroxidase increased the odds ratio for a history of myocardial infarction to 3.1 (CI, 1.5 to 6.3 ) in women who had subclinical hypothyroidism compared with euthyroid women who did not have antibodies to thyroid peroxidase (Table 3). Because only one woman with subclinical hypothyroidism and antibodies to thyroid peroxidase had myocardial infarction during follow-up, we were not

Table 2. Characteristics of Women according to Vascular Disease Status

\begin{tabular}{|c|c|c|c|}
\hline Characteristic & $\begin{array}{l}\text { All Women } \\
(n=1055)\end{array}$ & $\begin{array}{l}\text { Women with Aortic } \\
\text { Atherosclerosis } \\
(n=560)\end{array}$ & $\begin{array}{l}\text { Women with a History of } \\
\text { Myocardial Infarction } \\
\qquad(n=79)\end{array}$ \\
\hline Mean age $\pm S D, y$ & $68.9 \pm 7.5$ & $70.7 \pm 7.4$ & $71.1 \pm 6.9$ \\
\hline Median thyroid-stimulating hormone level (25th, 75th percentile), $\mathrm{mU} / \mathrm{L}$ & $1.7(1.1,2.7)$ & $1.7(1.1,2.8)$ & $2.0(1.2,3.4)$ \\
\hline Women with subclinical hypothyroidism, \% (n) & $11.8(124)$ & $13.9(78)^{*}$ & $21.5(17) \dagger$ \\
\hline Women with subclinical hypothyroidism and antibodies to thyroid & 58 (61) & $71(40) *$ & $139(11)+$ \\
\hline Women with antibodies to thyroid peroxidase, \% (n) & $21.6(228)$ & $21.4(120)$ & $26.6(21)$ \\
\hline
\end{tabular}

* $P<0.05$ compared with women without the specific vascular disease status (chi-square test).

$+P<0.01$ compared with women without the specific vascular disease status (chi-square test). 


\begin{tabular}{|c|c|c|c|c|}
\hline \multirow[t]{2}{*}{ Variable } & $\begin{array}{l}\text { Condition } \\
\text { Present }\end{array}$ & $\begin{array}{l}\text { Condition } \\
\text { Absent }\end{array}$ & $\begin{array}{l}\text { Odds Ratio } \\
(95 \% \mathrm{Cl}) \dagger\end{array}$ & $\begin{array}{l}\text { Odds Ratio } \\
(95 \% \mathrm{Cl}) \neq\end{array}$ \\
\hline & \multicolumn{2}{|c|}{$n$} & & \\
\hline \multicolumn{5}{|l|}{ Aortic atherosclerosis } \\
\hline Women with subclinical hypothyroidism & 77 & 37 & $1.7(1.1-2.6)$ & $1.9(1.2-3.1)$ \\
\hline Euthyroid women & 474 & 376 & $1 \S$ & \\
\hline Women with subclinical hypothyroidism and antibodies to thyroid peroxidase & 39 & 16 & $1.9(1.1-3.6)$ & $2.2(1.1-4.3)$ \\
\hline Euthyroid women without antibodies to thyroid peroxidase & 398 & 301 & $1 \S$ & $1 \S$ \\
\hline \multicolumn{5}{|l|}{ Myocardial infarction } \\
\hline Women with subclinical hypothyroidism & 17 & 99 & $2.3(1.3-4.0)$ & $2.3(1.3-4.2)$ \\
\hline Euthyroid women & 61 & 806 & $1 \S$ & \\
\hline Women with subclinical hypothyroidism and antibodies to thyroid peroxidase & 11 & 46 & $3.1(1.5-6.3)$ & $3.5(1.7-7.4)$ \\
\hline Euthyroid women without antibodies to thyroid peroxidase & 52 & 660 & $1 \S$ & $1 \S$ \\
\hline
\end{tabular}

able to compute the corresponding risk for incident myocardial infarction. No association was found between the presence of antibodies to thyroid peroxidase and history of myocardial infarction or between aortic atherosclerosis and history of myocardial infarction when thyroid status was not altered (data not shown).

From our data, we calculated an attributable risk percentage of 60 and a population attributable risk percentage of 14 for subclinical hypothyroidism associated with myocardial infarction (Table 4). If subclinical hypothyroidism is assumed to be causally related to myocardial infarction, our findings suggest that it contributed to $60 \%$ of cases of myocardial infarction among women affected by subclinical hypothyroidism and that it was involved in the pathogenesis of $14 \%$ of all myocardial infarctions in the study sample. For purposes of comparison, the attributable risk percentages and the population attributable risk percentages for hypercholesterolemia, hypertension, smoking, and diabetes associated with myocardial infarction in all female participants in the Rotterdam Study are presented in Table 4.

\section{Discussion}

Our results show that subclinical hypothyroidism is highly prevalent among elderly women and is associated with a greater frequency of aortic atherosclerosis and myocardial infarction. Among women with subclinical hypothyroidism, these associations are slightly stronger in those who have antibodies to thyroid peroxidase. Thyroid autoimmunity itself is not associated with aortic atherosclerosis or myocardial infarction.

One limitation of our study is the cross-sectional nature of the design, which necessitates careful in- terpretation of the results. The relative risk for myocardial infarction in women with subclinical hypothyroidism in the prospective part of our study was similar to the point estimate in the cross-sectional part of our study. However, the CI was wide and included 1.0. Furthermore, we must consider the fact that elevated TSH levels may be caused by nonthyroidal illness $(31,32)$. However, we excluded women with a low free thyroxine level and observed that women with subclinical hypothyroidism did not differ from euthyroid women in levels of total protein, albumin, and creatinine. Therefore, it is highly unlikely that nonthyroidal illness affected the validity of our results. Serum samples were obtained only from women who visited the research center. We assume that the nonresponse for the visit to the research center will not depend on subclinical hypothyroidism differently among persons with or without the presence of cardiovascular disease, making selection bias unlikely. Furthermore, follow-up information was not available for all study participants as a result of logistic reasons. Because we have no reason to assume that the relation between subclinical hypothyroidism and myocardial infarction in women with complete follow-up data differs from this association in those without followup data, we do not believe that this lack of information influenced the validity of our results.

Approximately $11 \%$ of women in our sample had a TSH level greater than $4 \mathrm{mU} / \mathrm{L}$. This prevalence closely resembles that reported in women in the Wickham survey (5), the Framingham Study (6), and a study in community-dwelling elderly persons (33). Among all women in our sample for analysis, $13(1.1 \%)$ had unrecognized overt thyroid failure characterized by an elevated TSH level $(>4.0$ $\mathrm{mU} / \mathrm{L})$ and an abnormal free thyroxine level $(<11$ $\mathrm{pmol} / \mathrm{L}[0.9 \mathrm{ng} / \mathrm{dL}])$, which is in agreement with reports of prevalence found during screening (4). 
These data suggest that our sample is representative of the general population.

Several studies on the association between coronary heart disease and subclinical hypothyroidism have been done. Our results agree with those of previous case-control studies that also showed an association between subclinical hypothyroidism and coronary heart disease in elderly women $(9,10)$. However, a Finnish study that presented results of men and women together provided no evidence that latent thyroid failure is associated with coronary heart disease (7). Female patients with coronary heart disease were shown to have significantly lower serum levels of TSH than controls; however, subclinical hypothyroidism did not seem to be related to the presence of coronary heart disease (11). In the Wickham survey, no cross-sectional association with ischemic heart disease was observed, but a weak association between minor electrocardiographic changes and minor degrees of hypothyroidism was found in women (8).

Data on atherosclerosis and subclinical hypothyroidism are scarce. A case-control study in elderly women suggested an association between subclinical hypothyroidism and peripheral arterial disease (34). We are the first to describe an association between subclinical hypothyroidism and atherosclerosis as assessed by a noninvasive measurement in a general population sample. Aortic atherosclerosis was diagnosed by radiographic detection of calcified deposits in the abdominal aorta, which has been shown to be a highly specific technique for the measurement of aortic intima atherosclerosis (21). False-negative misclassification may have occurred in our study, but it was probably independent of thyroid status and therefore may have affected our results only by causing us to underestimate the association. Because we found that subclinical hypothyroidism was associated with both atherosclerosis and myocardial infarction, our data may indicate that atherosclerosis is involved in the mechanism by which subclinical hypothyroidism and myocardial infarction are associated.

Several mechanisms that may be involved with the association of subclinical hypothyroidism with atherosclerosis and myocardial infarction can be considered. A common cause of thyroid failure in elderly women is autoimmune thyroiditis $(6,35)$. It has been suggested that pathologic immune reactivity (for example, immune complex-mediated vascular damage) may be important in the association of autoimmune thyroiditis with coronary heart disease (36). However, the literature on this association is controversial. Some studies have described an association between thyroid autoimmunity and coronary heart disease $(9,10,12,14,37)$, and other studies have not $(7,8,11,15)$. Different uses of various
Table 4. Attributable Risk Percentages and Population Attributable Risk Percentages for Subclinical Hypothyroidism and Classic Risk Factors for Cardiovascular Disease Associated with Incident Myocardial Infarction in Women in the Rotterdam Study

\begin{tabular}{|c|c|c|c|}
\hline \multirow[t]{2}{*}{ Risk Factor } & \multirow[t]{2}{*}{$\begin{array}{l}\text { Age-Adjusted } \\
\text { Relative Risk* }\end{array}$} & $\begin{array}{l}\text { Attributable } \\
\text { Risk }\end{array}$ & $\begin{array}{c}\text { Population } \\
\text { Attributable Risk }\end{array}$ \\
\hline & & \multicolumn{2}{|r|}{$\%$} \\
\hline Subclinical hypothyroidism & 2.5 & 60 & 14 \\
\hline Hypercholesterolemia & 2.4 & 58 & 18 \\
\hline Hypertension & 1.6 & 38 & 14 \\
\hline Smoking & $2.0 / 1.2 \dagger$ & $50 / 17 \neq$ & 15 \\
\hline Diabetes mellitus & 2.4 & 58 & 14 \\
\hline
\end{tabular}

generations of antibody assays and different definitions of thyroid autoimmunity may have played a role in these discrepant findings. We found no association between the presence of antibodies to thyroid peroxidase itself and aortic atherosclerosis or myocardial infarction, which weakens the notion that a pathologic immune reactivity is important. We found that associations between subclinical hypothyroidism and aortic atherosclerosis or myocardial infarction were slightly stronger when subclinical hypothyroidism was accompanied by antibodies to thyroid peroxidase. This suggests that subclinical hypothyroidism, which is thought to be more severe and lasting in the presence of thyroid antibodies, contributes to the pathogenesis of cardiovascular disease.

Some authors found a disturbance in the atherogenic lipid metabolism in patients with subclinical hypothyroidism (38-42), whereas other studies did not (43-45). Although in our study the total cholesterol level was higher in women with overt hypothyroidism than in euthyroid women (data not shown), we did not find that total cholesterol level was higher in women with subclinical hypothyroidism than in euthyroid women. High-density lipoprotein and total cholesterol levels provided no pathophysiologic explanation for the association of subclinical hypothyroidism with aortic atherosclerosis and myocardial infarction. Other lipids-such as low-density lipoprotein cholesterol level, enhanced low-density lipoprotein oxidation (46), triglyceride level, and lipoprotein(a) level (42) - may be responsible for the association between subclinical hypothyroidism and cardiovascular disease, but we did not measure these factors.

Other mechanisms that may be involved in the association between subclinical hypothyroidism and cardiovascular disease can be derived from experimental data. In vitro, thyroid hormones inhibit 
collagen-induced platelet aggregation $(47,48)$ and directly relax smooth muscle (49). These effects may be important if thyroid hormones have the same effects in adult humans, although in subclinical hypothyroidism, by definition, levels of thyroid hormones are not decreased. Hypothyroidism is accompanied by a hypercoagulable state (50), increased blood viscosity (51), and a greater plasma concentration of total homocysteine (52); if these factors are also seen in subclinical hypothyroidism, they may account for atherosclerotic and ischemic disorders.

In conclusion, we found that subclinical hypothyroidism is highly prevalent in elderly women and is strongly and independently associated with aortic atherosclerosis and myocardial infarction. The population attributable risk percentage for subclinical hypothyroidism associated with myocardial infarction was within the range of that for known major risk factors for cardiovascular disease. Additional research should be done to determine whether this association can be confirmed in a prospective study. If not, subsequent studies may focus on the effectiveness of possible therapies for subclinical hypothyroidism in elderly women and the desirability of screening such women for this disorder.

From Erasmus University Medical School, Rotterdam, the Netherlands.

Acknowledgments: The authors thank the participants of the Rotterdam Study for participation and the research physicians and assistants of the Rotterdam Study for data collection. They also thank Professor Roel Doctor for supervision of laboratory measurements and Mr. Hans van Toor for performing the laboratory measurements.

Grant Support: By a grant from the Health Research and Development Council, The Hague, the Netherlands (no. 28.2897) (Dr. Witteman).

Requests for Single Reprints: Jacqueline C.M. Witteman, PhD, Department of Epidemiology and Biostatistics, Erasmus University Medical School, PO Box 1738, 3000 DR Rotterdam, the Netherlands; e-mail, witteman@epib.fgg.eur.nl.

Requests To Purchase Bulk Reprints (minimum, 100 copies): Barbara Hudson, Reprints Coordinator; phone, 215-351-2657; e-mail, bhudson@mail.acponline.org.

Current Author Addresses: Drs. Hak, Hofman, and Witteman: Department of Epidemiology and Biostatistics, Erasmus University Medical School, Box 1738, 3000 DR Rotterdam, the Netherlands.

Drs. Pols and Visser: Department of Internal Medicine III, Erasmus University Medical School, Box 1738, 3000 DR Rotterdam, the Netherlands.

Dr. Drexhage: Department of Immunology, Erasmus University Medical School, Box 1738, 3000 DR Rotterdam, the Netherlands.

Author Contributions: Conception and design: A.E. Hak, H.A.P. Pols, A. Hofman, J.C.M. Witteman.

Analysis and interpretation of the data: A.E. Hak, H.A.P. Pols,

T.J. Visser, H.A. Drexhage, J.C.M. Witteman.

Drafting of the article: A.E. Hak.

Critical revision of the article for important intellectual content: H.A.P. Pols, T.J. Visser, H.A. Drexhage, A. Hofman, J.C.M. Witteman.
Final approval of the article: A.E. Hak, H.A.P. Pols, T.J.

Visser, H.A. Drexhage, A. Hofman, J.C.M. Witteman.

Statistical expertise: A.E. Hak, J.C.M. Witteman.

Obtaining of funding: A. Hofman, J.C.M. Witteman.

\section{References}

1. Vanhaelst L, Neve P, Chailly P, Bastenie PA. Coronary-artery disease in hypothyroidism. Observations in clinical myxoedema. Lancet. 1967;2:800-2.

2. Steinberg AD. Myxedema and coronary artery disease-a comparative autopsy study. Ann Intern Med. 1968;68:338-44.

3. Klein I, Ojamaa K. The cardiovascular system in hypothyroidism. In: Braverman LE, Utiger RD, eds. Werner and Ingbar's the Thyroid. 7th ed. Philadelphia: Lippincott-Raven; 1996:799-804.

4. Helfand M, Redfern CC. Clinical guideline, part 2. Screening for thyroid disease: an update. American College of Physicians. Ann Intern Med. 1998; 129:144-58.

5. Tunbridge WM, Evered DC, Hall R, Appleton D, Brewis M, Clark F, et al. The spectrum of thyroid disease in a community: the Wickham survey. Clin Endocrinol (Oxf). 1977;7:481-93.

6. Sawin CT, Castelli WP, Hershman JM, McNamara P, Bacharach P. The aging thyroid. Thyroid deficiency in the Framingham Study. Arch Intern Med. 1985; 145:1386-8

7. Heinonen OP, Gordin A, Aho K, Punsar S, Pyorala K, Puro K. Symptomless autoimmune thyroiditis in coronary heart-disease. Lancet. 1972;1: 785-6.

8. Tunbridge WM, Evered DC, Hall R, Appleton D, Brewis M, Clark F, et al. Lipid profiles and cardiovascular disease in the Whickham area with particular reference to thyroid failure. Clin Endocrinol (Oxf). 1977;7:495-508.

9. Tièche M, Lupi GA, Gutzwiller F, Grob PJ, Studer H, Burgi H. Borderline low thyroid function and thyroid autoimmunity. Risk factors for coronary heart disease? Br Heart J. 1981;46:202-6.

10. Dean JW, Fowler PB. Exaggerated responsiveness to thyrotrophin releasing hormone: a risk factor in women with coronary artery disease. Br Med J (Clin Res Ed). 1985;290:1555-61.

11. Miura S, litaka M, Suzuki S, Fukasawa N, Kitahama S, Kawakami Y, et al. Decrease in serum levels of thyroid hormone in patients with coronary heart disease. Endocr J. 1996;43:657-63.

12. Bastenie PA, Vanhaelst L, Neve P. Coronary-artery disease in hypothyroidism. Lancet. 1967;2:1221-2.

13. Gaspar IA. Postmortem observations on the thyroid in atherosclerosis. J Am Geriatr Soc. 1968;16:686-95

14. Bastenie PA, Vanhaelst L, Bonnyns M, Neve P, Staquet M. Preclinical hypothyroidism: a risk factor for coronary heart-disease. Lancet. 1971;1:203-4.

15. Vanderpump MP, Tunbridge WM, French JM, Appleton D, Bates D, Clark F, et al. The development of ischemic heart disease in relation to autoimmune thyroid disease in a 20-year follow-up study of an English community. Thyroid. 1996;6:155-60.

16. Hofman A, Grobbee DE, de Jong PT, van den Ouweland FA. Determinants of disease and disability in the elderly: the Rotterdam Elderly Study. Eur J Epidemiol. 1991;7:403-22.

17. van Gent CM, van der Voort HA, de Bruyn AM, Klein F. Cholesterol determinations. A comparative study of methods with special reference to enzymatic procedures. Clin Chim Acta. 1977;75:243-51.

18. Trantow T, Herzog R, Gegenheimer L, Lucker PW. A new method for the determination of the bioavailability of thyroid hormone preparations. Methods Find Exp Clin Pharmacol. 1994;16:133-40

19. Witteman JC, Grobbee DE, Valkenburg HA, van Hemert AM, Stijnen T, Hofman A. Cigarette smoking and the development and progression of aortic atherosclerosis. A 9-year population-based follow-up study in women. Circulation. 1993;88(5 Pt 1):2156-62.

20. Witteman JC, Grobbee DE, Valkenburg HA, van Hemert AM, Stijnen T, Burger $\mathbf{H}$, et al. J-shaped relation between change in diastolic blood pressure and progression of aortic atherosclerosis. Lancet. 1994;343:504-7.

21. Hyman JB, Epstein FH. A study of the correlation between roentgenographic and post-mortem calcifications of the aorta. Am Heart J. 1954;48: 540-3.

22. Bots ML, Witteman JC, Grobbee DE. Carotid intima-media wall thickness in elderly women with and without atherosclerosis of the abdominal aorta. Atherosclerosis. 1993;102:99-105.

23. Witteman JC, Kannel WB, Wolf PA, Grobbee DE, Hofman A, D'Agostino RB, et al. Aortic calcified plaques and cardiovascular disease (the Framingham Study). Am J Cardiol. 1990;66:1060-4.

24. Witteman JC, Kok FJ, van Saase JL, Valkenburg HA. Aortic calcification as a predictor of cardiovascular mortality. Lancet. 1986;2:1120-2.

25. van Bemmel JH, Kors JA, van Herpen G. Methodology of the modular ECG analysis system MEANS. Methods Inf Med. 1990;29:346-53.

26. Willems JL, Abreu-Lima C, Arnaud $P$, van Bemmel JH, Brohet $C_{\text {, }}$ Degani R, et al. The diagnostic performance of computer programs for the interpretation of electrocardiograms. N Engl J Med. 1991;325:1767-73.

27. International Statistical Classification of Diseases and Related Health Problems, 10th Revision. v 1. World Health Organization. Geneva: World Health Organization; 1992

28. Harjai KJ, Licata AA. Effects of amiodarone on thyroid function. Ann Intern Med. 1997;126:63-73.

29. Brass EP. Effects of antihypertensive drugs on endocrine function. Drugs. 1984;27:447-58 
30. Hennekens $\mathrm{CH}$, Buring JE. Epidemiology in Medicine. v 1. Boston: Little, Brown; 1987.

31. Wong ET, Bradley SG, Schultz AL. Elevations of thyroid-stimulating hormone during acute nonthyroidal illness. Arch Intern Med. 1981;141:873-5.

32. Brent GA, Hershman JM, Braunstein GD. Patients with severe nonthyroidal illness and serum thyrotropin concentrations in the hypothyroid range. Am J Med. 1986;81:463-6.

33. Parle JV, Franklyn JA, Cross KW, Jones SC, Sheppard MC. Prevalence and follow-up of abnormal thyrotrophin (TSH) concentrations in the elderly in the United Kingdom. Clin Endocrinol (Oxf). 1991;34:77-83.

34. Powell J, Zadeh JA, Carter G, Greenhalgh RM, Fowler PB. Raised serum thyrotrophin in women with peripheral arterial disease. Br J Surg. 1987;74: 1139-41.

35. Robuschi G, Safran M, Braverman LE, Gnudi A, Roti E. Hypothyroidism in the elderly. Endocr Rev. 1987:8:142-53.

36. Mathews JD, Whittingham S, Mackay IR. Autoimmune mechanisms in human vascular disease. Lancet. 1974;2:1423-7.

37. Bastenie PA, Vanhaelst L, Golstein J, Smets P. Asymptomatic autoimmune thyroiditis and coronary heart-disease. Cross-sectional and prospective studies. Lancet. 1977;2:155-8.

38. Fowler PB, Swale J, Andrews H. Hypercholesterolaemia in borderline hypothyroidism. Stage of premyxoedema. Lancet. 1970;2:488-91.

39. Althaus BU, Staub JJ, Ryff-De Leche A, Oberhansli A, Stahelin HB. LDL/HDL-changes in subclinical hypothyroidism: possible risk factors for coronary heart disease. Clin Endocrinol. 1988;28:157-63.

40. Caron P, Calazel C, Parra HJ, Hoff M, Louvet JP. Decreased HDL cholesterol in subclinical hypothyroidism: the effect of L-thyroxine therapy. Clin Endocrinol (Oxf). 1990;33:519-23.

41. Staub JJ, Althaus BU, Engler $H$, Ryff AS, Trabucco $P$, Marquardt $K$, et al. Spectrum of subclinical and overt hypothyroidism: effect on thyrotropin, prolactin, and thyroid reserve, and metabolic impact on peripheral target tissues. Am J Med. 1992;92:631-42.
42. Kung AW, Pang RW, Janus ED. Elevated serum lipoprotein(a) in subclinical hypothyroidism. Clin Endocrinol (Oxf). 1995;43:445-9.

43. Nilsson G, Nordlander S, Levin K. Studies on subclinical hypothyroidism with special reference to the serum lipid pattern. Acta Med Scand. 1976;200: 63-7.

44. Parle JV, Franklyn JA, Cross KW, Jones SR, Sheppard MC. Circulating lipids and minor abnormalities of thyroid function. Clin Endocrinol (Oxf). 1992;37:411-4.

45. Geul KW, van Sluisveld IL, Grobbee DE, Docter R, de Bruyn AM, Hooykaas $\mathbf{H}$, et al. The importance of thyroid microsomal antibodies in the development of elevated serum TSH in middle-aged women: associations with serum lipids. Clin Endocrinol (Oxf). 1993;39:275-80.

46. Sundaram V, Hanna AN, Koneru L, Newman HA, Falko JM. Both hypothyroidism and hyperthyroidism enhance low density lipoprotein oxidation. J Clin Endocrinol Metab. 1997;82:3421-4.

47. Mamiya S, Hagiwara M, Inoue S, Hidaka H. Thyroid hormones inhibit platelet function and myosin light chain kinase. J Biol Chem. 1989:264:8575-9.

48. Masaki H, Nishikawa M, Urakami M, Yoshimura M, Toyoda N, Mori Y, et al. 3,3',5'-Triiodothyronine inhibits collagen-induced human platelet aggregation. J Clin Endocrinol Metab. 1992;75:721-5.

49. Ishikawa T, Chijiwa T, Hagiwara M, Mamiya S, Hidaka H. Thyroid hormones directly interact with vascular smooth muscle strips. Mol Pharmacol. 1989;35:760-5.

50. Chadarevian R, Bruckert E, Ankri A, Beucler I, Giral P, Turpin G. Relationship between thyroid hormones and plasma D-dimer levels. Thromb Haemost. 1998;79:99-103.

51. Koltringer P, Eber O, Wakonig P, Klima G, Lind P. Hypothyroidism and the influence on human blood rheology. J Endocrinol Invest 1988:11:267-72.

52. Nedrebo BG, Ericsson UB, Nygard O, Refsum H, Ueland PM, Aakvaag A, et al. Plasma total homocysteine levels in hyperthyroid and hypothyroid patients. Metabolism. 1998;47:89-93. 